\title{
Formula to Predict Transmission for $\pi$-Type Floating Breakwaters
}

\author{
Piero Ruol ${ }^{1}$; Luca Martinelli²; and Paolo Pezzutto ${ }^{3}$
}

\begin{abstract}
The aim of this paper is to define a simple and useful formula to predict wave transmission for a common type of floating breakwater $(\mathrm{FB})$, supplied with two lateral vertical plates protruding downward, named $\pi$-type FB. Eight different models, with mass varying from 16 to $76 \mathrm{~kg}$, anchored with chains, have been tested in the wave flume of the Maritime Laboratory of Padova University, under irregular wave conditions. Water elevation in front and behind the structure has been measured with two arrays of four wave gauges. Our starting point for the prediction of wave transmission was the classical relationship established by Macagno in 1954. His relationship was derived for a box-type fixed breakwater assuming irrotational flow. Consequently, he significantly underestimated transmission for short waves and large drafts. This paper proposes an empirical modification of his relationship to properly fit the experimental results and a standardized plotting system of the transmission coefficient, based on a simple nondimensional variable. This variable is the ratio between the peak period of the incident wave and an approximation of the natural period of the heave oscillation. A fairly good accuracy of the prediction is found analyzing the data in the literature relative to variously moored $\pi$-type FBs, tested in small-scale wave tanks under regular and irregular wave conditions. DOI: 10.1061/ (ASCE)WW.1943-5460.0000153. ㅇ 2013 American Society of Civil Engineers.
\end{abstract}

CE Database subject headings: Breakwaters; Flumes; Wave measurement; Floating structures.

Author keywords: Floating breakwater; $\pi$-type; Wave flume experiments; Moorings; Natural oscillations; Wave transmission.

\section{Introduction}

This paper investigates the performance of a specific type of prefabricated chain-moored floating breakwater (FB), typically used to protect small marinas in mild sea conditions (wave periods up to $4.0 \mathrm{~s}$, wave heights smaller than $1.5 \mathrm{~m}$ ). The cross section of the FB type examined is a rectangular caisson with two vertical plates protruding downward from the sides. Because the shape of this cross section resembles the Greek letter $\pi$, it is referred to as $\pi$-type FB (Gesraha 2006).

FBs are usually composed of a series of adjacent interconnected modules set in a convenient layout and individually moored. An overview of the FB behavior is given in Hales (1981). The wave energy incident on the FB is partially reflected, partially dissipated, and only in part transmitted to the leeward side. The transmission coefficient $k_{t}$ is defined as the ratio between the transmitted and incident wave height and is used to express the FB efficiency in protecting the leeward side.

Generally, FBs reflect waves less than traditional breakwaters extending all the way to the seabed.

The vertical plates in the $\pi$-type FB are a low-cost solution to increase draft, and thus to enhance wave reflection (as in the case of the T-shape FB; Blumberg and Cox 1998; Neelamani and Rajendran

${ }^{1}$ ICEA, Univ. of Padova, Via Ognissanti 39, 35129 Padova, Italy (corresponding author). E-mail: piero.ruol@unipd.it

${ }^{2}$ ICEA, Univ. of Padova, Via Ognissanti 39, 35129 Padova, Italy. E-mail: luca.martinelli@unipd.it

${ }^{3}$ ICEA, Univ. of Padova, Via Ognissanti 39, 35129 Padova, Italy. E-mail: paolo.pezzutto@studenti.unipd.it

Note. This manuscript was submitted on September 12, 2011; approved on March 15, 2012; published online on March 19, 2012. Discussion period open until June 1, 2013; separate discussions must be submitted for individual papers. This paper is part of the Journal of Waterway, Port, Coastal, and Ocean Engineering, Vol. 139, No. 1, January 1, 2013. CASCE, ISSN 0733-950X/2013/1-1-8/\$25.00.
2002). The vertical plates are also effective in inducing vortices at the FB edges and in increasing dissipation.

The incident wave applies a load to the FB, whose movementslimited by the mooring system (Rahman et al. 2006; Loukogeorgaki and Angelides 2005, 2009) — play an important role in the process. The pair of plates beneath the FB confines a volume of fluid forcing it to move with the floating body, and therefore the added mass of the FB is increased by the confined mass. This favorably affects the overall dynamics, as subsequently shown. If the two attached plates are too long, however, they may behave as radiating wave sources, decreasing FB efficiency in short wave sea states, as observed by Christian (2000) on Alaska-type devices.

No simple formula suitable to $\pi$-type FB is available. The basic formula for the box-type FB behavior is the well-established Macagno's (1954) relationship, which assumes irrotational flow, linear waves, and a fixed structure. Predictions are qualitatively correct but are generally inaccurate when compared with laboratory and prototype results, especially when the wave is short or the draft is large compared with water depth. Other simple equations have been proposed, such as that of Ursell (1947), Wiegel (1960), Jones (1971), or Drimer et al. (1992). However, they all assume that the FB is rectangular and constrained to a fixed position, therefore neglecting the effect of movements.

Oliver et al. (1994) show that the FB system dynamics are specific for each installation because of the combination of the mooring system, water depth, and structure geometry. Therefore, for each design, new physical model tests and numerical simulations are required.

Values of $k_{t}$ based on physical model tests may be found in wellknown studies, such as Hales (1981) or Tolba (1998). More recent investigations that rely on improved measurement systems and analysis are also available (e.g., Koutandos et al. 2005; Gesraha 2006; Behzad and Akbari 2007; Dong et al. 2008; Cox et al. 2007; Peña et al. 2011; Ozeren et al. 2011).

Scale effects are mainly associated with dissipation phenomena and overtopping. Through large-scale tests, Koutandos et al. (2005) 
examined the behavior of four FB configurations of different shapes under both regular and irregular wave conditions. They observed that a vertical plate, protruding downward from the front of the FB, significantly enhanced the efficiency of the structure, increasing dissipation and therefore reducing transmission. Koftis et al. (2006) showed that, by numerical simulation, protruding plates act as turbulent energy sources, which dissipate wave energy.

The general conclusion of these two papers is that model scales that are too small to reach high-turbulent flow are likely to lead to slight underestimation of the full-scale $k_{t}$ for high waves. In fact, dissipation increases faster than wave height and does not follow the Froude law. Therefore, the effects of wave steepness should preferably be studied on large-scale models. Influence of other parameters appears to be correctly represented by scale models.

One might expect that a careful selection of previous research based on criteria, such as structure, mooring system, model scale, small-wave steepness conditions, and correct identification of incident and reflected waves (Mansard and Funke 1980; Zelt and Skjelbreia 1992), enables us to predict $k_{t}$, also for new cases comprised in the data set range.

On the contrary, the experimental results, frequently given in terms of a relationship between $k_{t}$ and $w / L$, with $w$ being the structure width and $L$ being the wavelength, are not applicable as such to other FBs of the same kind.

This happens because $w / L$ does not control the essence of the process.

The general aim of this work is to suggest a simple method for the evaluation of $k_{t}$ for a generic $\pi$-type FB, which can be achieved with the following two approaches: (1) by plotting the experimental results in a more effective way and (2) by means of a simple formula.

The first approach is to devise a standardized plotting system of the transmission coefficient, based on a simple nondimensional variable that reduces the variance of the experimental $k_{t}$ curves relative to different geometries. The procedure was first introduced by Martinelli et al. (2008) and Ruol et al. (2008), where the results relative to a $\pi$-type FB are given as function of $T_{p} / T_{h}$, with $T_{p}$ being the peak wave period, and $T_{h}$ being the natural period for the heave oscillation (for laterally confined structure, i.e., high length/width ratio).

Thanks to the choice of $T_{p} / T_{h}$ (as an alternative to $w / L$ ), the transmission and reflection coefficients for different structures appeared to be described by approximately the same line. One possible reason for this interesting behavior is that the response amplitude operator usually shows a peak in correspondence of a wave with a frequency equal to the natural frequency, and by using the suggested scaling variable, all the peaks occur at the same abscissa. Of the six degrees of freedom of the FB, only the heave oscillation has been selected because: (1) only the response to the frontal waves is considered in wave tank tests, and other movements (sway, jaw, and pitch) are not present; (2) heave always exists and is not considerably affected by the mooring type, whereas, for instance, surge-free oscillations are dominated by the horizontal mooring rigidity; (3) heave contributes in a high degree to the formation of the transmitted wave field; and (4) in a numerical code, the heave motion can be evaluated considering one degree of freedom only, because it is usually uncoupled from the other modes.

Unfortunately, in the $\pi$-type $\mathrm{FB}, T_{h}$ cannot be easily evaluated because of the complex geometry of the structure, which renders necessary a simplifying approximation, and therefore a new nondimensional variable.

The second approach is the development of a simple empirical formula capable of roughly predicting $k_{t}$ for chain-moored $\pi$-type FBs. The tests used to derive the formula were carried out in the wave flume at the University of Padova, Italy. Eight different $\pi$-type FBs, modeled in approximately 1:10 scale, are fitted to an empirical formula designed as a multiplication factor of Macagno's relationship. In fitting the formula, the decision was taken not to focus on the minor influence of the wave height on transmission observed in the experiments but on the FB dynamics, characterized by the same nondimensional variable previously mentioned.

This paper will first describe the physical model tests and then the new formula and the nondimensional variable proposed for the standardized plotting system. The subsequent section will compare the results of $k_{t}$ derived from the literature with the formula predictions. Final conclusions will be drawn, enhancing the limitation of the proposed approaches.

\section{Experimental Investigation}

Physical model tests have been carried out in the Maritime Laboratory of the University of Padova. The wave flume is 36-m long, $1-\mathrm{m}$ wide, and 1.4-m deep. The rototranslating wave generator is equipped with an active absorption system.

All the studied $\pi$-type FBs were built using aluminum with a polystyrene core (Fig. 1). The general scheme and the notation are given in Fig. 2. Fig. 3 shows one of the models moored in the wave flume.

Part of the tests addressed are described in conference proceedings (Ruol and Martinelli 2007; Ruol et al. 2008, 2010). Tests relative to the structure with a larger mass are presented for the first time.

Several irregular wave conditions (JONSWAP spectra with a 3.3 shape factor) were generated, forming a grid with different periods and different wave steepness, using the paddle in piston mode and an active wave absorption system. Table 1 shows all the tested wave attacks, although they were not all reproduced for all structures (e.g., higher and longer waves were not studied in the case of small structures).

Table 2 summarizes the geometry of the whole set of investigations carried out in the wave flume at different stages between 2005 and 2011. Table 2 also includes one additional model tested in the wave basin (last line in Table 2) under perpendicular waves. All the flume tests were performed with a depth at the structure equal to $0.515 \mathrm{~m}$. The basin test was performed with a depth of $0.500 \mathrm{~m}$.

Each investigation is characterized by a model code that identifies the studied structure and configuration. This code convention was also used in Ruol et al. (2010) and Martinelli et al. (2008). In the code, the first letter is not important in this context. The second letter describes the mooring system ( $c=$ chains, $p=$ piles, $t=$ tethered,...); a digit for the structure orientation ( 0 if perpendicular to the waves); a digit for the facility hosting the tests ( $c=$ flume, $v=$ basin); and eventually a group of four characters with the target model mass and its unit measure $(x x k g)$.

Different mooring configurations, piles, and chains were investigated. Chains (with a submerged weight of $78 \mathrm{~g} / \mathrm{m}$ ) were anchored at a point distant twice the water depth from the fairlead. The chain angle at the bottom was typically $16^{\circ}$ (250 g horizontal

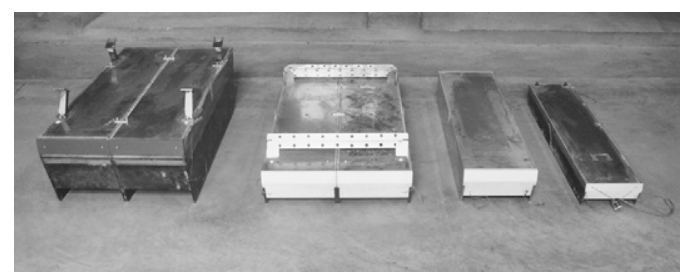

Fig. 1. Tested floating breakwater of weights $76,32,16$, and $7 \mathrm{~kg}$; the smallest unit was investigated in the wave basin and described in Martinelli et al. (2008) 


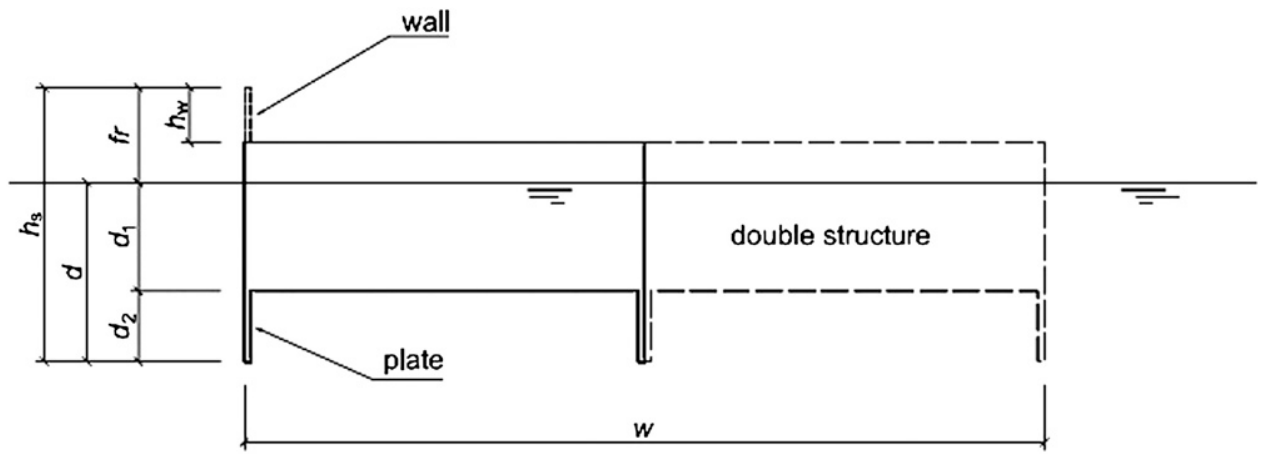

Fig. 2. Floating breakwater general scheme

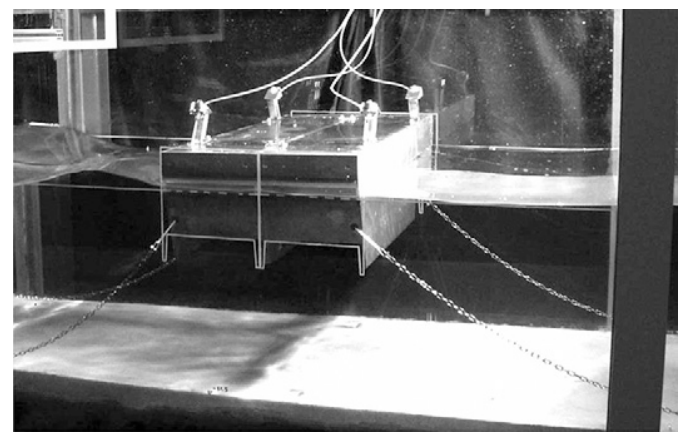

Fig. 3. Example of investigated structure $(D c 0 c 56 \mathrm{~kg})$

Table 1. Characteristics of Irregular Wave Attacks (significant wave height, $H_{s}$, and peak period $T_{p}$ )

\begin{tabular}{lccccccc}
\hline & \multicolumn{7}{c}{$T_{p}(s)$} \\
\cline { 2 - 8 }$H_{s}(\mathrm{~cm})$ & 0.45 & 0.56 & 0.67 & 0.78 & 0.89 & 1.01 & 1.12 \\
\hline 1.5 & $\mathrm{X}$ & $\mathrm{X}$ & $\mathrm{X}$ & & & & \\
2.5 & $\mathrm{X}$ & $\mathrm{X}$ & $\mathrm{X}$ & $\mathrm{X}$ & $\mathrm{X}$ & $\mathrm{X}$ & $\mathrm{X}$ \\
3.5 & $\mathrm{X}$ & $\mathrm{X}$ & $\mathrm{X}$ & $\mathrm{X}$ & $\mathrm{X}$ & $\mathrm{X}$ & $\mathrm{X}$ \\
4.5 & & $\mathrm{X}$ & $\mathrm{X}$ & $\mathrm{X}$ & $\mathrm{X}$ & $\mathrm{X}$ & $\mathrm{X}$ \\
5.5 & & & $\mathrm{X}$ & $\mathrm{X}$ & $\mathrm{X}$ & $\mathrm{X}$ & $\mathrm{X}$ \\
6.5 & & & & $\mathrm{X}$ & $\mathrm{X}$ & $\mathrm{X}$ & $\mathrm{X}$ \\
7.5 & & & & & $\mathrm{X}$ & $\mathrm{X}$ & $\mathrm{X}$ \\
8.5 & & & & & & & $\mathrm{X}$ \\
\hline
\end{tabular}

pretension). A more and a less compliant mooring case were also investigated, being the horizontal pretension equal to 150 and $350 \mathrm{~g}$, respectively.

The two $76 \mathrm{~kg}$ structures in Table 2 have a geometry that fills a gap in the data set of the literature results. They were investigated in the framework of a FP7 project (THESEUS 2012).

The setups of the first eight series of tests in Table 2 are very similar. In fact they include eight resistive wave gauges, grouped into two arrays of four gauges each, placed $3 \mathrm{~m}$ in front or behind the structure (Fig. 4). In some tests, two position transducers, one hinged on the leeward corner and one on the windward corner of the FB, were used to measure the body dynamics.

Gauge signals were postprocessed with the procedure of Zelt and Skjelbreia (1992) for separating incident and reflected wave trains.

To measure natural frequencies and damping factors, free decay tests were performed. The observed natural period of heave oscillation $T_{h}$ is included in Table 2 .
Fig. 5 shows all test results as a function of $T_{p} / T_{h}$. For each model and configuration, several $k_{t}$ are plotted, referring to different wave conditions.

When there is resonance in heave motion, the transmission is around $50 \%$. For larger $T_{p} / T_{h}$ ratios, that is, for waves of a long period, the transmission coefficient increases, as expected. On the other hand, for $T_{p} / T_{h}$ smaller than 1 , that is, for short periods, the transmission coefficient decreases again, as expected.

\section{Proposed Formula}

This section proposes a new formula for the evaluation of $k_{t}$, given in the form of a simple correction to Macagno's relationship, accounting for the dynamic effects of the $\pi$-shaped FB.

Macagno's relationship, based on four variables, is first recalled. A combination of these variables is then introduced, indicated by $\chi$, which will be shown to be just a simplification of $T_{p} / T_{h}$.

Finally, the proposed correction formula, $\beta$, is a simple fitting of the ratio between experimental $k_{t}$ and numerical $k_{t}$ obtained using Macagno's prediction, expressed as a function of $\chi$.

\section{Macagno’s Formula}

According to Macagno's formula, the transmission coefficient for a rectangular, fixed, and infinitely long breakwater with draft $d$ and width $w$, subject to regular waves, is estimated by

$$
k_{t M}=\frac{1}{\sqrt{1+\left[k w \frac{\sinh k h}{2 \cosh (k h-k d)}\right]^{2}}}
$$

where $k(=2 \pi / L)$ is the wavenumber and $h$ is the water depth. Macagno's relationship was derived for rectangular, box-type, fixed breakwater; therefore, it may be applied to predict transmission coefficients for this kind of structures only.

The formula has intrinsic limitations, for example, if draft $d$ is equal to depth $h$, some transmission is predicted whereas none is expected.

The application of the formula to a FB undergoing motions in one or more degrees of freedom rather than a fixed breakwater is common, although arbitrary.

In fact, the linear process described by Macagno (1954) does not account for radiated waves.

When applied to represent the transmission for irregular wave conditions, the regular wavelength is substituted by an average wavelength derived on the basis of the mean wave period. The even more arbitrary application of Macagno's relationship to $\pi$-type FBs 
Table 2. Tested Models Geometries (Notation in Fig. 2) and Configurations

\begin{tabular}{|c|c|c|c|c|c|c|c|c|c|}
\hline Model code & Mass (kg) & $w(\mathrm{~m})$ & $h_{s}(\mathrm{~m})$ & $d_{1}(\mathrm{~m})$ & $d_{2}(\mathrm{~m})$ & $f r(\mathrm{~m})$ & $h_{w}(\mathrm{~m})$ & Moorings & $T_{h}$ \\
\hline $\mathrm{NcOcl6kg}$ & 16.20 & 0.250 & 0.150 & 0.065 & 0.035 & 0.050 & - & Chains $^{\mathrm{a}}$ & 0.88 \\
\hline Sc0cl6kg & 16.20 & 0.250 & 0.150 & 0.065 & 0.035 & 0.050 & - & Chains $^{\mathrm{b}}$ & 0.88 \\
\hline SpOcl6kg & 17.50 & 0.250 & 0.150 & 0.070 & 0.035 & 0.045 & - & Piles & 0.88 \\
\hline SfOcl6kg & 17.50 & 0.250 & 0.150 & 0.070 & 0.035 & 0.045 & - & Chains $^{c}$ & 0.88 \\
\hline $\mathrm{Dc} 0 \mathrm{c} 32 \mathrm{~kg}$ & 32.00 & 0.500 & 0.150 & 0.065 & 0.035 & 0.050 & - & Chains $^{\mathrm{a}}$ & 1.05 \\
\hline Dc0c56kg & 56.30 & 0.500 & 0.283 & 0.111 & 0.067 & 0.105 & - & Chains $^{\mathrm{a}}$ & 1.17 \\
\hline $\mathrm{Dc} 0 \mathrm{c} 76 \mathrm{~kg}$ & 76.30 & 0.500 & 0.283 & 0.171 & 0.067 & 0.045 & - & Chains $^{\mathrm{a}}$ & 1.30 \\
\hline $\mathrm{Mc} 0 \mathrm{c} 76 \mathrm{~kg}$ & 76.30 & 0.500 & 0.343 & 0.171 & 0.067 & 0.105 & 0.060 & Chains $^{\mathrm{a}}$ & 1.30 \\
\hline 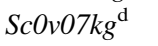 & 7.25 & 0.200 & 0.100 & 0.035 & 0.030 & 0.035 & - & Chains $^{\mathrm{a}}$ & 0.75 \\
\hline
\end{tabular}

${ }^{\mathrm{a}}$ Different value of initial horizontal tension in the chains $(250 \mathrm{~g})$.

${ }^{b}$ Different value of initial horizontal tension in the chains $(130 \mathrm{~g})$.

${ }^{c}$ Different value of initial horizontal tension in the chains (350 g).

${ }^{\mathrm{d}}$ Carried out in wave basin, setup described in Martinelli et al. (2008).

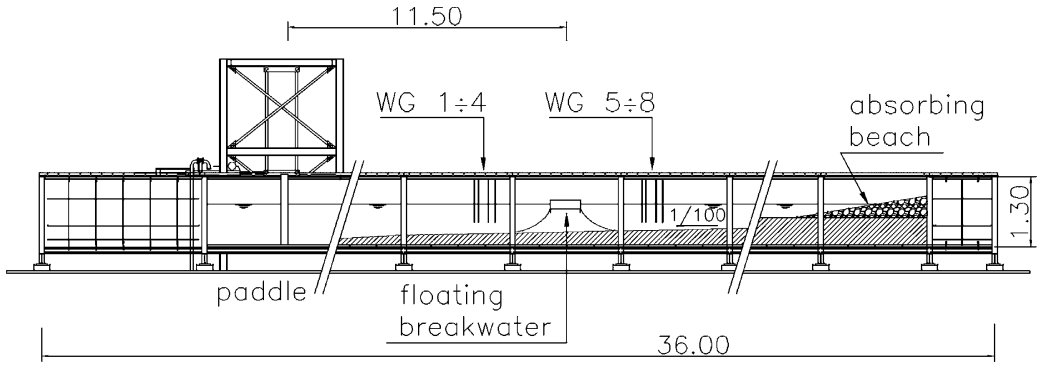

Fig. 4. Experimental setup (not to scale)

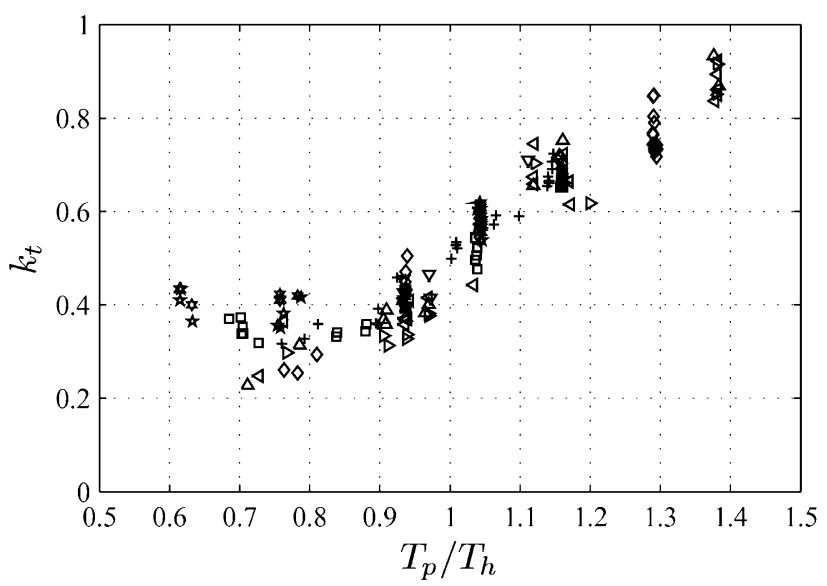

Fig. 5. Distribution of measured $k_{t}$ for the whole set of investigated structures: data are distributed with respect to nondimensional period $T_{p} / T_{h}$; plus symbol, $S c 0 v 07 \mathrm{~kg}$; left triangle, $N c 0 c 16 \mathrm{~kg}$; upward triangle, $S c 0 c 16 \mathrm{~kg}$; right triangle, $S p 0 c 16 \mathrm{~kg}$; downward triangle, $S f 0 c 16 \mathrm{~kg}$; diamond, DcOc32kg; square, DcOc56kg; star, Dc0c76kg; asterisk, $M c 0 c 76 \mathrm{~kg}$

is expected to be at least inaccurate. Therefore, a corrective formula is searched for in this case.

\section{New Dimensionless Variable}

The formula that shall be developed aims at overcoming the incorrect prediction of Macagno's relationship with respect to the experimental results. The formula is a function of a dimensionless variable, which interprets the FB dynamic effects.
As previously anticipated, one candidate is $T_{p} / T_{h}$, which unfortunately is difficult to define, because the natural period of heave oscillation is not easily available.

The somewhat circuitous search for an alternative nondimensional variable produced a result that is a good approximation of $T_{p} / T_{h}$.

$T_{h}$, or the corresponding $\omega_{h}\left(=2 \pi / T_{h}\right)$, is found using the equation for the natural frequency of a simplified vertical undamped oscillation of a floating body, neglecting possible coupling terms of the heave motion with the rest of the motions of the structures [Eq. (2)]

$$
\omega_{h}=\sqrt{K / M}
$$

where $K=$ vertical stiffness and $M=$ overall mass of the system. $K$ is given by the buoyancy forces and the mooring stiffness in the vertical direction. Because moorings are hardly designed to restrain the vertical movements of the FB, the stiffness is totally dominated by the buoyancy forces $F$.

Because a two-dimensional problem is discussed, all quantities are given per unit length (length of $\mathrm{FB}=1$ ), and $F$ is given by

$$
F=\rho_{w} g w y=K y
$$

where $w=$ FB width, $y=$ vertical coordinate, $\rho_{w}=$ water density, and $g=$ acceleration of gravity.

The overall system mass $M$ is the sum of the structure mass $M_{s}$ and the added mass $M_{a}$, which is essentially the mass of water that accelerates with the body.

In Fig. 6, $M_{a}$ is simplified by the water mass trapped in between the two plates and the water mass trapped in half of a circle of the radius equal to half of the $\mathrm{FB}$ width $w$.

According to Fig. 6, the added mass in two-dimensions is assessed as 


$$
\tilde{M}_{a}=\rho_{w}\left(w d_{2}+\pi w^{2} / 8\right)
$$

Because the body mass is equal to the mass of the displaced water, the total estimated mass may be evaluated as

$$
M_{s}+\tilde{M}_{a}=\rho_{w}\left(w d_{1}+w d_{2}+\pi w^{2} / 8\right)=\rho_{w} w(d+0.39 w)
$$

Replacing Eqs. (3) and (5) in the general expression of heave natural frequency Eq. (2), an estimated expression for the heave natural frequency is obtained as follows:

$$
\tilde{\omega}_{h}=\sqrt{\frac{g}{d+0.39 w}}
$$

A regression analysis (Fig. 7) was performed based on experimental evaluation of the natural frequency, producing the following:

$$
\widehat{\omega}_{h} \approx \sqrt{\frac{g}{d+0.35 w}}
$$

which reflects the database geometries and is not much different from Eq. (6).

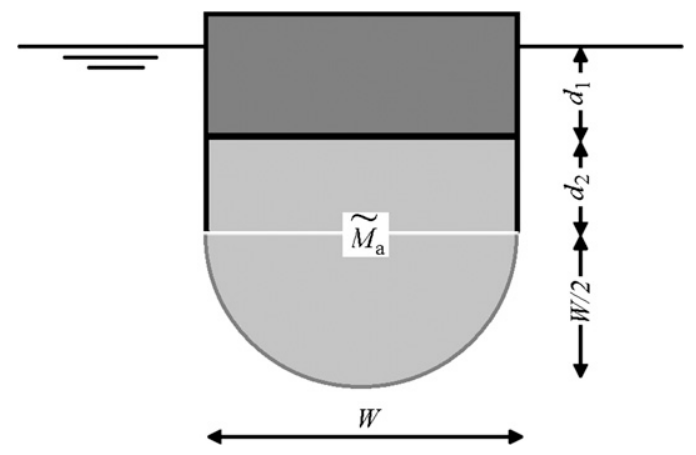

Fig. 6. Added mass and the submerged part of the floating breakwater

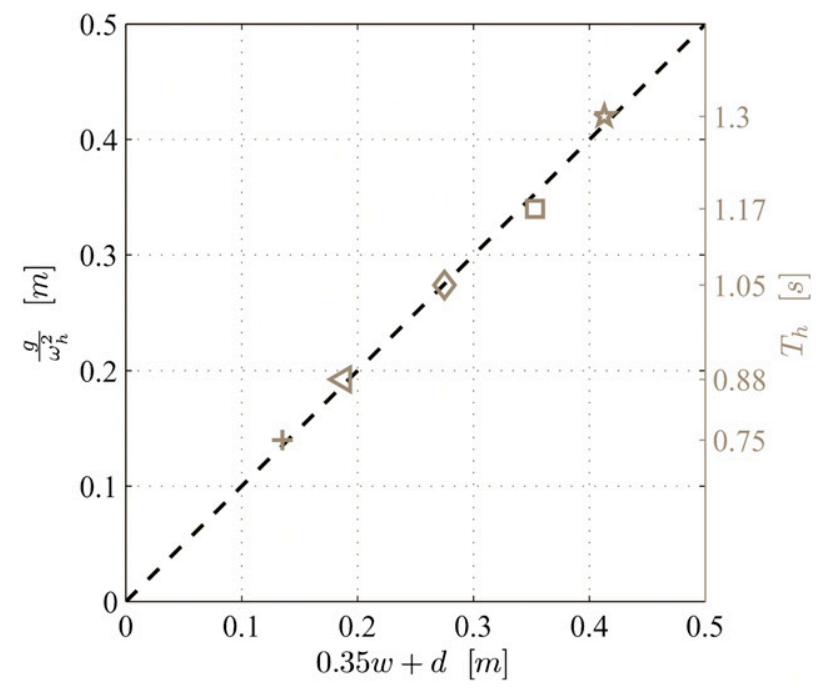

Fig. 7. Linear regression of heave natural frequencies; plus symbol, $S c 0 v 07 \mathrm{~kg}$; left triangle, $\mathrm{NcOcl6kg}$; diamond, $D c 0 c 32 \mathrm{~kg}$; square, Dc0c56kg; star, Dc0c76kg
The assumption for the added mass (and the consequent calculation of the natural period of oscillation) is questionable, but it gives quite good approximation of real investigated cases, as proved by Fig. 7.

Eq. (7) could also be justified numerically. The semicircularshaped added mass [second term in Eq. (4)] is half of the added mass relative to a plate moving in an unbounded fluid, that is, in absence of a free surface (Sarpkaya and Isaacson 1981). In the presence of a free surface, the added mass is frequency dependent, $\mathbf{M}_{a}(\omega)$, and may be found solving the classical radiation problem (Newman 1977; Chakrabarti 1987). The natural oscillation is found iteratively computing $\mathrm{M}_{a}(\omega)$ for $\omega=\omega_{h}$ (Mays 1997; Senjanovic et al. 2008). The theoretical $T_{h}$ (obtained from the model described in Martinelli and Ruol 2006) is 5\% shorter than the measured one for the smallest FB (7 kg), whereas good agreement is found for the larger structures $(16-76 \mathrm{~kg})$. According to the numerical model, Eq. (7) slightly underestimates the theoretical values for structures with extreme widths and drafts.

The assumed scaling parameter $\chi \approx T_{p} / T_{h}$ is obtained directly from Eq. (7)

$$
\chi=\frac{T_{p}}{2 \pi} \sqrt{\frac{g}{d+0.35 w}}
$$

Because $\chi$ is much easier to find than $T_{p} / T_{h}$ and has essentially the same value, the authors propose that the experimental results of $k_{t}$ are always plotted as a function of $\chi$.

To see the dependence of Macagno's formula on $\chi$, or, more precisely, on $T / 2 \pi \sqrt{g /(d+0.35 w)}$ with $T$ instead of $T_{p}$, because Macagno's relationship refers to regular waves, Eq. (1) was applied to a wide range of the three parameters involved, namely $k h \in[0.1 ; 10], k w \in[0.1 ; 10]$, and $k d \in[0.01 ; 5]$, obtaining the $k_{t}$ values shown in Fig. 8. The whole set of data falls within a limited region, proving that $T / 2 \pi \sqrt{g /(d+0.35 w)}$ explains most of the variance of the formula. Great variance of $k_{t M}$ is observed for $\chi$ below 1 . This is expected because for long periods the water depth $h$ (not accounted for in $\chi$ ) becomes important.

The $\chi$ parameter can be expressed in terms of the wavelength (and water depth) instead of the period, by means of the dispersion relationship. This choice appears more suited in the case of oblique wave attacks, because the wave obliquity can be satisfactorily

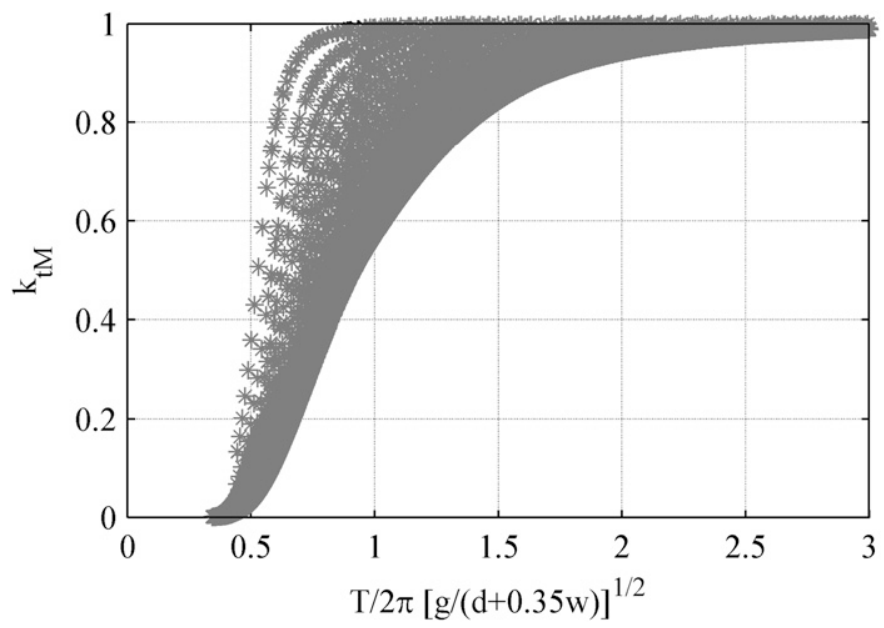

Fig. 8. Distribution of Macagno's values for $k w \in[0.1 ; 10], k d \in$ [0.01;5], and $k h \in[0.1 ; 10]$ : the wavenumber $k$ is a function of wave period $T$ through the linear dispersion relation 
represented by the perpendicular component of the wavelength (Ruol et al. 2011).

Finally, a discussion on $T_{p}$ is necessary. $T_{p}$ is usually an input variable in laboratory experiments, but should be better re-evaluated in postprocessing. In these tests, $T_{p}$ is obtained by evaluating the center of gravity of the upper one-third of the spectrum, and it is approximately $10 \%$ larger than the mean period $T$. In fact, evaluation of $k_{t}$ according to Macagno's relationship is carried out assuming $T \cong T_{p} / 1.1$.

\section{New Formula}

Fig. 9 shows the ratios between Macagno's predicted values and the laboratory data, plotted versus $\chi$.

Macagno's relationship overestimates wave transmission with respect to small-scale measurements when the natural period is close to the peak period, that is, for $\chi \in[0.8 ; 1.3]$, which usually represents a design condition $\left(k_{t}\right.$ of the order of 0.5$)$ and underestimates wave transmission for short waves $(\chi<0.8)$. Good agreement is found in the area far from the design conditions $(\chi>1.3)$. Close to $\chi=0.95$ (Fig. 9), a sensitive spread in the data is observed.

It is reasonable to express a correction function $\beta(\chi)$, which relates the transmission coefficient $k_{t}$ of a general $\pi$-type FB to the one derived analytically for a fixed rectangular breakwater using Macagno's relationship, that is, $k_{t M}$ [Eq. (1)]. In other words it is assumed that

$$
k_{t}=\beta(\chi) k_{t M}
$$

As previously mentioned, for higher waves, higher dissipation and overtopping are expected, both involving processes that are affected by the model scale. In fact, the effect of the wave height on transmission was marginal, and a clear tendency was not identified. To minimize the scale effect related to overtopping, the fitting only involved the cases with incident wave heights smaller than the freeboard $\left(H_{i}<f r\right)$

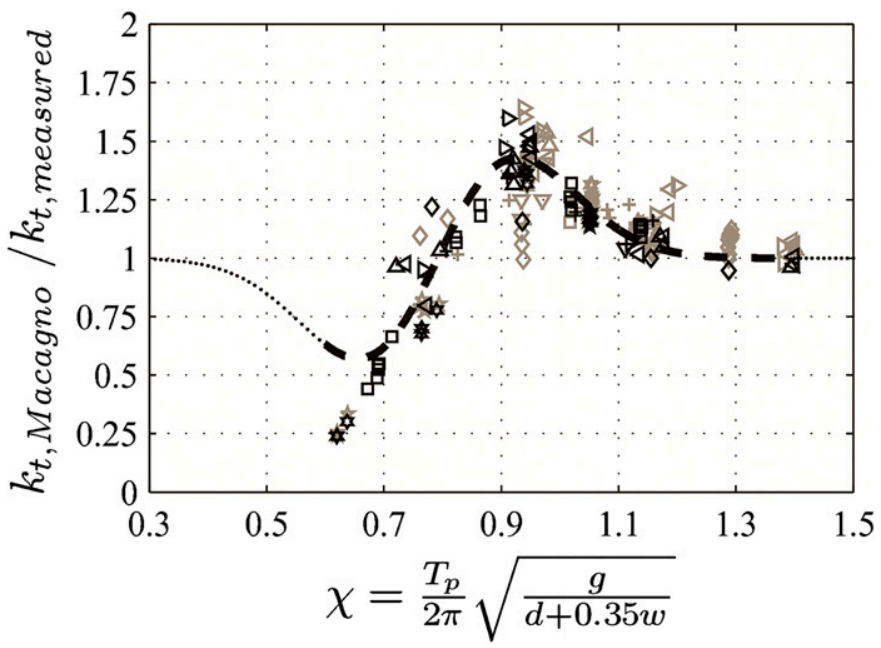

Fig. 9. Qualitative goodness of Macagno's prediction in terms of $k_{t M} / k_{t}$ for the whole database; plus sign, $S c 0 v 07 \mathrm{~kg}$; left triangle, NcOcl6kg; upward triangle, Sc0c16kg; right triangle, $S p 0 c 16 \mathrm{~kg}$; downward triangle, $S f 0 c 16 \mathrm{~kg}$; diamond, $D c 0 c 32 \mathrm{~kg}$; square, $D c 0 c 56 \mathrm{~kg}$; star, Dc0c76kg; asterisk, Mc0c76kg: correction $\beta^{-1}$ [Eq. (10)] to Macagno's relationship [Eq. (1)]; long dashed lines, investigated range; short dashed lines, extrapolation; black symbols for fitted data $\left(H_{s}>f_{r}\right)$, gray symbols for discarded data $\left(H_{s}>f_{r}\right)$
To find a suitable equation for $\beta$, based on a number of parameters limited as much as possible, the authors imposed the boundary condition $k_{t}=k_{t M}$ for very long and very short waves, in agreement with experience, resulting in $\beta=1$ for $\chi>1.3$ and $\chi<0.3$. Both cases are out of the practical range of interest, because $k_{t}=1$ for very long waves and $k_{t}=0$ for very short waves.

The following formula fits the experimental data reasonably well, spanning the range $\chi \in(0.5 ; 1.5)$

$$
\beta=\frac{1}{1+\left(\frac{\chi-\chi_{o}}{\sigma}\right) e^{-\left(\frac{\chi-\chi_{o}}{\sigma}\right)^{2}}}
$$

where $\chi_{o}=0.7919$ (with $95 \%$ confidence interval $0.7801,0.8037$ ) and $\sigma=0.1922(0.1741,0.2103)$.

Fig. 9 shows the inverse of Eq. (10), that is, $\beta^{-1}$, to emphasize the fitting error for $\chi$ in the range of interest and to avoid logscale plots. The experimental data relative to the first eight cases included in Table 2 (i.e., the wave flume investigations) were used to find $\beta$. Data are grouped into two sets, representing nonovertopping and overtopping sea states, and are plotted using black and gray symbols. The first set, used for the fitting, is well described by the formula, and the RMS error is 0.12 . For the second set of data (relative to wave heights larger than the FB freeboard, $f_{r}$ ), the RMS error (for the prediction of $\left.k_{t M} / k_{t}\right)$ is 0.13 .

Fig. 9 only presents tests relative to the same water depth. The effect of the water depth is therefore not directly investigated. It could affect the dynamics of the system and the stiffness of the mooring lines.

\section{Validation}

Validation is based on test results of wave transmission published in recent literature, relative to $\pi$-type FBs, with any kind of mooring (fixed breakwaters are obviously excluded). In all considered cases, reported in Table 3, a modern analysis technique is used, including separation of incident and reflected waves.

To validate the proposed model [Eqs. (9) and (10)], Fig. 10 shows the comparison between the computed transmission coefficient and available results gathered from the literature.

When the comparison involves tests with regular waves, indicated by empty symbols in Fig. 10, the wave period is considered equivalent to the significant period of an irregular wave. To use

\begin{tabular}{|c|c|c|}
\hline Number & Study & Notes \\
\hline 1 & Martinelli et al. (2008) & $\begin{array}{l}\text { Moored with chains, small } \\
\text { structure tested in wave } \\
\text { basin. Only perpendicular } \\
\text { waves are considered here. }\end{array}$ \\
\hline 2 & Gesraha (2006) & $\begin{array}{l}\text { Moored with chains, under } \\
\text { regular wave conditions. }\end{array}$ \\
\hline 3 & Koutandos et al. (2005) & $\begin{array}{l}\text { Only vertical translation } \\
\text { allowed, tests under regular } \\
\text { wave conditions. }\end{array}$ \\
\hline 4 & Cox et al. (2007) & $\begin{array}{l}\text { Moored with piles, regular } \\
\text { and irregular wave } \\
\text { conditions. }\end{array}$ \\
\hline 5 & Peña et al. (2011) & $\begin{array}{l}\text { Moored with chains, three } \\
\text { structures tested under } \\
\text { regular wave conditions }\end{array}$ \\
\hline
\end{tabular}

Table 3. Experimental Studies Considered for Validation

Note: Tests causing large overtopping are excluded. 


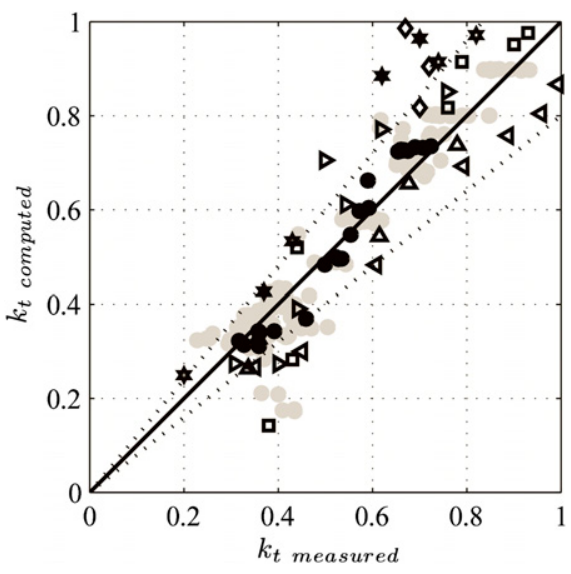

Fig. 10. Predictions of $k_{t}$ compared with literature data: dotted lines represent $\pm 20 \%$ confidence limits: empty symbols are relative to regular waves; shaded circle, present work; solid circle, Martinelli et al. (2008); square, Gesraha (2006); diamond, Koutandos et al. (2005); open asterisk, (regular) Cox et al. (2007); solid asterisk, (irregular) Cox et al. (2007); left triangle, (Model A) Peña et al. (2011); upward triangle, (Model B) Peña et al. (2011); right triangle, (Model C) Peña et al. (2011)

Eq. (8), a multiplication factor of 1.1 is applied to the tested regular wave period to transform it into an equivalent peak period.

Coherently, when the comparison involves tests with irregular waves, Macagno's relationship (suited to regular waves only) is evaluated by computing the equivalent average wavelength on the basis of the available peak period divided by 1.1.

More than $50 \%$ of the literature data lie in between the $20 \%$ confidence region (Fig. 10). An excellent agreement with the freely moving $\pi$-type FB of Gesraha (2006) and Martinelli et al. (2008) and a good agreement for the three models described in Peña et al. (2011) is obtained.

Measured transmission coefficients related to FB where sway is not allowed, such as when piles are used for the mooring (Cox et al. 2007) or when the roll is fully restrained (Koutandos et al. 2005), are generally overestimated by our corrective model by an average of $20 \%$. This result was expected, because the different mooring characteristics, not accounted for by the formula, are important to define the FB performance.

\section{Conclusions}

Eight different $\pi$-type FB models have been tested under irregular long-crested waves in the Maritime Laboratory of Padova University, in approximately 1:10 scale.

The results are plotted against a combination of parameters [Eq. (8)] that appear to govern the whole set of transmission coefficients measured in our experiments. The new nondimensional parameter is the ratio between the peak period of the incident waves and a simplistic approximation of the natural period of heave oscillation.

Macagno's relationship, developed for fixed box-type breakwaters, is taken as a starting point to include the effect of draft, width, water depth, and wavelength. To compute the transmission coefficient of floating, chain-moored $\pi$-type FBs, a correction formula that fits the experimental measurements, a function of the aforementioned nondimensional parameter, is proposed and analyzed in depth.

A comparison with literature small-scale results validates the formula, whose error is of the order of $20 \%$. Some scatter is to be expected, because the effect of wave height and mooring stiffness can hardly be included in a simple formula. Part of the scatter should also be attributed to the role played by Macagno's relationship, which was chosen for its prestige rather than its proven suitability to the purposes here.

Because scale effects are likely to affect the transmission phenomenon, especially in the case of high waves, with abundant overtopping, the formula was not intended to fit these cases. Therefore, it could be inaccurate in the presence of waves higher than the FB freeboard, especially in full-scale applications.

The new formula has been derived considering two-dimensional experimental data. Therefore, the diffraction effects arising from the finite length of the breakwater are not taken into account. However, in real situations, FBs consist of many floating units connected to each other. The effects of the wave angle and complex layouts both on wave transmission and the loads along the module interconnections are discussed in Martinelli et al. (2008) and Diamantoulaki and Angelides (2011).

\section{Acknowledgments}

The support of the European Union FP7 THESEUS "Innovative technologies for safer European coasts in a changing climate," contract ENV.2009-1, n. 244104, is gratefully acknowledged.

\section{References}

Behzad, M., and Akbari, M. (2007). "Experimental investigation on response and efficiency of moored pontoon type floating breakwaters." Iranian J. Sci. Technol. Trans. B Eng., 31(1), 95-99.

Blumberg, G. P., and Cox, R. J. (1988). "Floating breakwater physical model testing for marina applications." World Association for Waterborne Transport Infrastructure (PIANC) Bulletin No. 63, Brussels, Belgium.

Chakrabarti, S. K. (1987). Hydrodynamics of off-shore structures, WIT Press, Southampton, U.K.

Christian, C. D. (2000). "Floating breakwaters for small boat marina protection." Proc., 27th Int. Conf. on Coastal Engineering (ICCE), World Scientific, 2268-2277.

Cox, R., Coghlan, I., and Kerry, C. (2007). "Floating breakwater performance in irregular waves with particular emphasis on wave transmission and reflection, energy dissipation, motion and restraining forces." Proc., Coastal Structures, World Scientific, Singapore, 7(1), 351-362.

Diamantoulaki, I., and Angelides, D. C. (2011). "Modeling of cable-moored floating breakwaters connected with hinges." Eng. Struct., 33(5), 1536-1552.

Dong, G. H., et al. (2008). "Experiments on wave transmission coefficients of floating breakwaters." Ocean Eng., 35(8-9), 931-938.

Drimer, N., Agnon, Y., and Stiassnie, M. (1992). "A simplified analytical model for a floating breakwater in water of finite depth." Appl. Ocean Res., 14(1), 33-41.

Gesraha, M. R. (2006). "Analysis of $\Pi$ shaped floating breakwater in oblique waves: I. Impervious rigid wave boards." Appl. Ocean Res., 28(5), 327-338.

Hales, L. Z. (1981). "Floating breakwaters: State-of-the-art literature review." Technical Rep. TR81-1. United States Army Corps of Engineers, Springfield, VA.

Jones, D. B. (1971). "Transportable breakwaters-A survey of concepts." Technical Rep. R727, Naval Civil Engineering Laboratory, Port Hueneme, CA.

Koftis, T. H., Prinos, P., and Koutandos, E. (2006). "2D-V hydrodynamics of wave-floating breakwater interaction." J. Hydraul. Res., 44(4), 451-469.

Koutandos, E., Prinos, P., and Gironella, X. (2005). "Floating breakwaters under regular and irregular wave forcing-reflection and transmission characteristics." J. Hydraul. Res., 43(2), 174-188.

Loukogeorgaki, E., and Angelides, D. C. (2005). "Stiffness of mooring lines and performance of floating breakwaters in three dimensions." Appl. Ocean Res., 27(4-5), 187-208. 
Loukogeorgaki, E., and Angelides, D. C. (2009). "Status identification and optimum adjustment of performance of moored floating breakwaters." Int. J. of Offshore Polar Eng., 19(1), 31-41.

Macagno, E. O. (1954). "Houle dans un canal présentant un passage en charge." La Houille Blanche, 1(1), 10-37 (in French).

Mansard, E. P. D., and Funke, E. R. (1980). "The measurement of incident and reflected spectra using a least squares method." Proc., 17th Int. Conf. Coastal Eng., ASCE, Reston, VA, 154-172.

Martinelli, L., and Ruol, P. (2006). "2D model of floating breakwater dynamics under linear and nonlinear waves." Proc., 2nd COMSOL User Conf., COMSOL, Milan, Italy.

Martinelli, L., Ruol, P., and Zanuttigh, B. (2008). "Wave basin experiments on floating breakwaters with different layouts." Appl. Ocean Res., 30(3), 199-207.

Mays, T. W. (1997). "Three-dimensional analysis of moored cylinders used as breakwaters." M.S. thesis, Virginia Polytechnic Institute and State Univ., Blacksburg, VA.

Neelamani, S., and Rajendran, R. (2002). "Wave interaction with T-type breakwaters." Ocean Eng., 29(2), 151-175.

Newman, J. N. (1977). Marine hydrodynamics, MIT Press, Cambridge, MA.

Oliver, J. G., et al. (1994). "Floating breakwaters-A practical guide for design and construction." Rep. No. 13, World Association for Waterborne Transport Infrastructure (PIANC), Brussels, Belgium.

Ozeren, Y., Wren, D. G., Altinakar, M., and Work, P. A. (2011). "Experimental investigation of cylindrical floating breakwater performance with various mooring configurations." J. Waterway, Port, Coastal, Ocean Eng., 137(6), 300-309.

Peña, E., Ferreras, J., and Sanchez-Tembleque, F. (2011). "Experimental study on wave transmission coefficient, mooring lines and module connector forces with different designs of floating breakwaters." Ocean Eng., 38(10), 1150-1160.

Rahman, M. A., Mizutani, N., and Kawasaki, K. (2006). "Numerical modeling of dynamic responses and mooring forces of submerged floating breakwater." Coast. Eng., 53(10), 799-815.
Ruol, P., and Martinelli, L. (2007). "Wave flume investigation on different mooring systems for floating breakwaters." Proc., Coast. Struct., 7(1), 327-338.

Ruol, P., Martinelli, L., and Pezzutto, P. (2011). "Multi-chamber OWC devices to reduce and convert wave energy in harbour entrance and inner channels." Proc., Int. Offshore and Polar Engineering Conf., Maui, HI, Vol. 1, 622-629.

Ruol, P., Martinelli, L., and Zanuttigh, B. (2008). "2D and 3D experimental analysis on forces and performance of floating breakwaters." Proc., 2nd Int. Conf. Application of Physical Modelling to Port and Coastal Protection (CoastLab), International Association of Hydraulic Engineering and Research (IAHR), Bari, Italy, 557-572.

Ruol, P., Pezzutto, P., and Martinelli, L. (2010). "Analisi sperimentale sulla risposta 2D di molteplici frangiflutti galleggianti." Proc., XXXII Convegno di Idraulica e Costruzioni Idrauliche (IDRA), Walter Farina IT, Palermo, Italy (in Italian).

Sarpkaya, T., and Isaacson, M. (1981). Mechanics of wave forces on offshore structures, Van Nostrand-Reinhold, New York.

Senjanovic, I., Malenica, S., and Tomasevic, S. (2008). "Investigation of ship hydroelasticity." Ocean Eng., 35(5-6), 523-535.

THESEUS. (2012). "Innovative technologies for safer European coasts in a changing climate."〈http://www.theseusproject.eu〉(Jan. 1, 2012).

Tolba, E. R. A. S. (1998). "Behaviour of floating breakwaters under wave action." Ph.D. thesis, Suez Canal Univ., Port Said, Egypt.

Ursell, F. (1947). "The effect of a fixed vertical barrier on surface waves in deep water." Math Proc., Cambridge Philos. Soc., 43(3), 374-382.

Wiegel, R. L. (1960). "Transmission of waves past a rigid vertical thin barrier.” J. Waterway, Port, Coastal, Ocean Eng., 86(1), 1-12.

Zelt, J. A., and Skjelbreia, J. (1992). "Estimating incident and reflected wave fields using an arbitrary number of wave gauges." Proc., 23rd Int. Conf. Coastal Engineering (ICCE), ASCE, Vol. 1, Reston, VA, 777-789. 